The impact of the high ozone intrusions on the overall photochemistry of the tropical troposphere cannot be estimated from the data of Suhre et al. The authors have, however, clearly demonstrated the great opportunities and cost effectiveness offered by instrumentation on commercial aircraft. The results show again very clearly how little we know about tropospheric ozone in the tropics and subtropics, which are so important photochemically. Until these regions are much more intensely researched, the quanti- tative basis for chemical studies will remain weak. The participation of scientists from the tropics and subtropics in this research should be encouraged.

Paul Crutzen and Mark Lawrence are in the Max-Planck-Institut für Chemie, Abteilung Chemie der Atmosphäre, Postfach 3060, 55020 Mainz, Germany.

1. Suhre, K. et al. Nature 388, 661-663 (1997).

2. Chameides, W. L., Kasibhatla, P. S., Yienger, J. \& Levy, H. Science 264, 74-77 (1994)

3. Crutzen, P. J. \& Andreae, M. O. Science 250, 1669-1678 (1990).

4. Kley, D. et al. Science 274, 230-233 (1996).

\title{
Immunotherapy
}

\section{Fusion induces tumour rejection}

\section{Ian Hart and Camilo Colaco}

T he war on cancer has been waged with ever-increasing intensity over the past 30 years or so, using the weapons of surgery, radiotherapy and chemotherapy. But it has resulted, to date, in only limited advances. This has led to calls for the main directions of research to be realigned, from treatment to prevention ${ }^{1}$. But cancer therapy will be given a renewed impetus by a paper published in Nature Medicine by Kufe and co-workers ${ }^{2}$, who describe an elegant but simple strategy for the treatment of cancer using immunotherapy.

The idea of immunotherapy as a new approach may seem to be a contradiction in terms, since strategies based on this concept have been applied clinically for over 100 years, with limited success. Nonetheless, there is renewed optimism ${ }^{3,4}$, largely based on a better understanding of how our cytotoxic T lymphocytes (CTLs) respond to tumour cells ${ }^{5}$ (Fig. 1). Central to the induction of CTL responses are professional antigen-presenting cells. These include the B lymphocytes, mononuclear phagocytes and dendritic cells, which present antigen to the immune system in the context of major histocompatibility complex (MHC) class I and class II molecules ${ }^{6}$.

In a host of experiments over the past few years, dendritic cells have been used to process and present tumour antigens. This has generally been achieved by pulsing cultured dendritic cells with peptides eluted from class I MHC molecules ${ }^{7}$, tumour cell membranes $^{7}$ or RNA derived from the neoplastic cells ${ }^{8}$. Kufe and co-workers have pursued the alternative strategy of introducing tumour antigens into dendritic cells in the most straightforward way — by fusing entire tumour cells with cultured dendritic cells.

The authors found that when cells from the murine MC38 carcinoma were fused with bone-marrow-derived dendritic cells, they obtained fusion hybrids. These were then used to immunize syngeneic (genetically identical) mice, and they generated a strong antitumour activity in these animals. Interestingly, this antitumour activity seemed to involve both CD4- and CD8-positive T cells, in MHC class I- and II-restricted responses, respectively. This is in contrast to the largely CD8-positive, class I-restricted responses that have been observed when dendritic cells pulsed with antigen have been used as immunogens ${ }^{7}$. More excitingly and potentially of greater clinical significance - this antitumour activity occurred not only against primary tumours, but also against pre-established metastatic disease ${ }^{3}$.

The fusion of tumour cells with antigenpresenting cells is not a new concept, and it has already been achieved with activated B cells ${ }^{9}$. However, as Kufe and colleagues point out, the use of dendritic cells offers two additional advantages - they can prime naive CTLs, and they are easily accessible from peripheral blood or bone marrow. This availability of donor cells would be of considerable benefit in any human application. But what of the tumour-cell side? Obviously, the single 'swallow' of the MC38 tumour does not a 'summer make', and both the procedure and the magnitude of the antitumour effects will need to be verified in further animal models. Moreover, efficacy against rodent tumours is not a guarantee of success against human cancers. The authors warn of the inherent limitations of animal models but, with their approach, it may be the technical rather than conceptual aspects that limit easy transfer to the clinic.

Fusion followed by selection means that, if the procedure is to be applied to individual human tumours, the neoplastic cells must have the capacity for continuous in vitro proliferation - not necessarily an attribute of all primary cell cultures. In the work by Kufe and colleagues, no selectable markers seem to have been incorporated into the fusion partners. This, of course, is not a problem when pure populations of tumour cells are used. But if mixed populations are derived from patient material, how can we guarantee that anti-self responses will not be generated against normal cells? These might fuse with the dendritic cells as easily as the cancer cells do, and lead to undesirable anti-self responses on injection. One way to obviate such potential problems might be to create universal fuser lines of representative tumours, rather than relying on material from individual patients.

The work of Kufe and co-workers - with its dramatic effects on tumour burden and immunoprotection - is complementary to the encouraging results of other groups, which have used dendritic cells to stimulate naive $\mathrm{T}$ cells. For example, the pulsing of dendritic cells with tumour antigens in vitro generates both tumour-specific CTLs ${ }^{10}$ and tumour resistance in vivo ${ }^{8}$. The rejection of established tumour metastases ${ }^{3,7-10}$ parallels the anti-graft rejection responses in transplantation immunology induced by donor dendritic cells ${ }^{11}$. This potency of the immune response that is elicited by dendritic cells is also illustrated by their ability to break neonatal tolerance ${ }^{12}$.

These results are promising because they represent new approaches to targeted immunotherapy that are based on a greater appreciation of the mechanisms by which

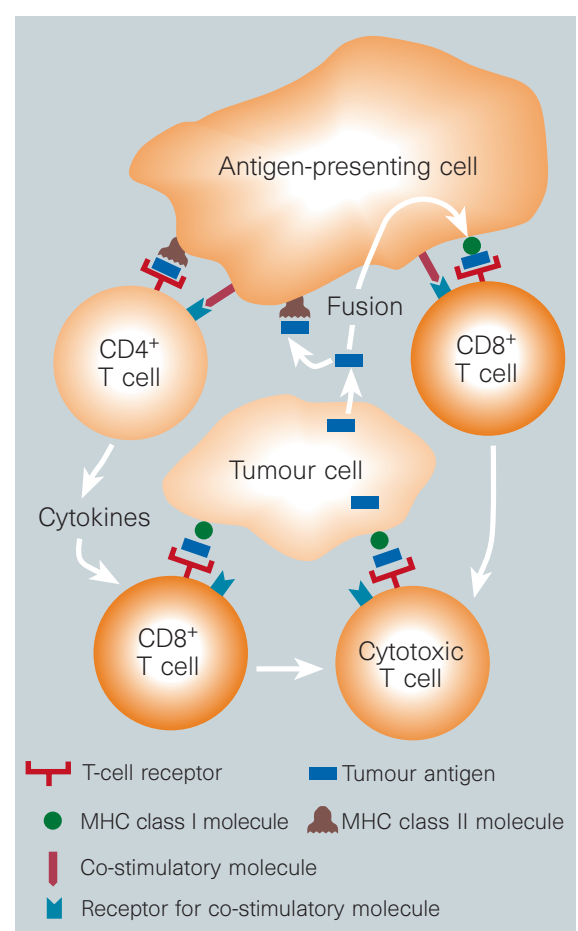

Figure 1 Kufe and colleagues ${ }^{2}$ have developed a new strategy to activate the response of cytotoxic T lymphocytes against tumour cells. Precytotoxic CD8-positive T lymphocytes may be primed directly by antigen-presenting cells, which present tumour antigens on a major histocompatibility complex (MHC) class I molecule. Presentation of tumour antigen by MHC class II molecules to CD4-positive helper T lymphocytes leads to the release of stimulatory cytokines, which activate the pre-cytotoxic CD8positive T lymphocytes. By fusing one group of antigen-presenting cells - the dendritic cells with entire tumour cells, the tumour antigens can be expressed and used to directly activate naive $\mathrm{T}$ lymphocytes. 
tumour-specific cytolytic cells are generated. Whether this will eventually represent a turning point in the war against cancer, or whether it is yet another false dawn, considerably more work still needs to be done. But at least the initial battle-plans look hopeful, and there is reason for optimism.

Ian Hart is in the Division of Oncology, United Medical Schools of Guy's and St Thomas' Hospitals, London SE1 7EH, UK. Camilo Colaco is at Quadrant Healthcare, Maris Lane, Cambridge CB2 2SY, UK.
Bailar J. C \& Gornik H. L N. Engl J Med 336, 1569-1574 (1997).

2. Gong, J., Chen, D., Kashiwaba, M. \& Kufe, D. Nature Med. 3, 558-561 (1997).

3. Vlasveld, L.T.\&Rankin,E. M.Cancer Treat. Rev. 20, 275-311 (1994).

4. Pardoll, D. M. Curr. Opin. Immunol. 5, 705-706 (1993).

5. Marland, G. et al. Stem Cells 14, 501-503 (1996)

6. Young, J. W. \& Inaba, K. J. Exp. Med. 183, 7-11 (1996).

7. Flamand, V. et al. Eur. J. Immunol. 24, 605-610 (1994).

8. Boczkowski, D. et al. J. Exp. Med. 184, 465-472 (1996).

9. Guo, Y. et al. Science 263, 518-520 (1994).

10. Bakkar, A. B. H. et al. Cancer Res. 55, 5330-5334 (1995).

11. Matzinger, P. Annu. Rev. Immunol. 12, 991-1045 (1994).

12. Ridge, J. P. et al. Science 271, 1723-1726 (1996).

Biodiversity

\section{Global change through invasion}

\section{Gábor L. Lövei}

nvasion by plants and animals occurs everywhere, and has profoundly influenced the shape of the world's biota over geological time. From the very early stages of agriculture, humans have also intentionally transported crops and animals to other regions of the world, thus greatly advancing the material culture of different societies ${ }^{1}$; the introduction of many more organisms was not so welcome. Today, the scale of species introduction by humans is vastly increased. Vitousek et al., in a paper in the New Zealand Journal of Ecology $y^{2}$, argue that species introductions should be recognized as an important component of human-induced global change and as a serious threat to biodiversity.

Invading plant and animal species have caused drastic changes in the receiving biota of islands like New Zealand or Hawaii, as testified by their recent history. Vitousek et al.'s carefully constructed, extensive list of plant invasions now allows us to look at this phenomenon from a more global perspective. Introduced species make up 26-40 per cent of all plant species in isolated regions (Table 1), and even more on islands: for example, 82 per cent of Ascension Island's biota is composed of introduced species. Regions with a high volume of trade generally have more introduced species than less frequented areas. What is surprising, though, is that continental areas are no exceptions. Introduced species make a significant contribution both in terms of the number of species per unit area and as their relative share in the flora (Table 1). There are some striking examples for vertebrates too: New Zealand's fish fauna contains 30 'exotic' species ( 53 per cent of the total), Puerto Rico's has a whopping 91 per cent, and even Brazil has 13 per cent ${ }^{2}$.

Invaders frequently make a heavy impact. The eastern North American deciduous forests have suffered larger perturbations by invading pests and pathogens than from pollution or acid rain $^{3}$. The long-term global effects of invasions are also significant, in two ways. First, they decrease the distinctiveness of local floras and faunas. New Zealand today has more vertebrate species than at the time of human colonization about 1,000 years ago $^{4}$. Even if the extinctions are not considered (all but one of the 50 extinct species were endemic to New Zealand), only one of the introduced species, the Australian parma wallaby (Macropus parma), is threatened in its homeland ${ }^{5}$. So although New Zealand has become more 'diverse', it has also become more similar to the rest of the world. Second, geographic isolation is necessary for the maintenance of global biodiversity. For example, the area of a continent and the number of mammal species it supports show a tight correlation (Fig. 1). If all the Earth's dryland area formed one supercontinent, the predicted global total would be only about half of the actual global species richness (Fig. 1). Similar relationships have been found for several other groups of

\begin{tabular}{|c|c|c|c|c|}
\hline \multirow[t]{2}{*}{ Region/country } & \multicolumn{2}{|c|}{ Number of species } & \multirow[b]{2}{*}{ Exotic/(log) area } & \multirow[t]{2}{*}{ Percentage of exotics } \\
\hline & Native & Exotic & & \\
\hline Russian Arctic & 1,403 & 104 & 15.9 & 6.9 \\
\hline Europe & 11,820 & 721 & 102.8 & 5.7 \\
\hline United States & 17,300 & 2,100 & 304.6 & 10.8 \\
\hline Southern Africa & 20,573 & 824 & 128.1 & 3.9 \\
\hline Australia & 15,638 & 1,952 & 283.5 & 11.1 \\
\hline Ontario & 2,056 & 805 & 133.5 & 28.1 \\
\hline New York state & 1,940 & 1,083 & 210.7 & 35.8 \\
\hline Perth region, Australia & 1,510 & 547 & 136.1 & 26.6 \\
\hline British Isles & 1,255 & 945 & 175.4 & 42.9 \\
\hline Hawaii & 1,143 & 891 & 210.9 & 43.8 \\
\hline New Zealand & 2,449 & 1,623 & 298.9 & 39.9 \\
\hline
\end{tabular}

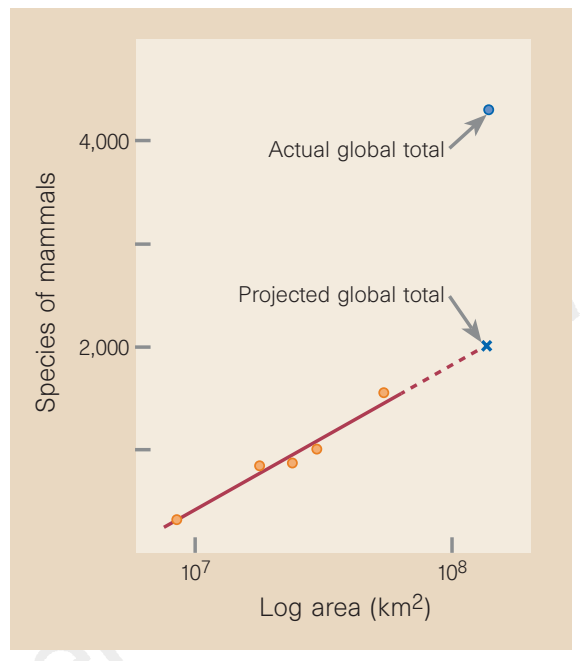

Figure 1 Species versus area curve for mammals. The number of species on a continent is tightly correlated with the size of the continent, but extrapolating that relation to the land area of Earth yields less than half the total number of species that actually occur on these continents. Much of the global diversity of mammalian species is due to the isolation of separate biotic regions. (Analysis prepared by A. Launer. Reproduced from ref. 2.)

organisms $^{6}$. The current human-assisted massive invasions could, in fact, create one 'supercontinent', and with the geographical barriers broken down, the inevitable result would be a catastrophic loss of biodiversity.

Why have species introductions not been recognized as a global phenomenon? Acknowledged components of global change, like ozone depletion or carbon dioxide enrichment (the 'greenhouse effect'), occur on a very large spatial scale and simultaneously affect several different ecosystems. In contrast, invasions are mostly local, and involve a few species acting over a relatively short time frame. A more cohesive view was called for in order to demonstrate that although the players and the location of the ecological 'theatres' may be different, the same 'evolutionary play' is being continuously enacted all over the world. And we constantly busy ourselves with transporting the players from one theatre to another.

Possibly, because natural invasions are going on all the time, just like species extinctions, it was conceptually difficult to recognize the global implications. Species extinction is a problem not because it is a new phenomenon, but because its rate far exceeds the rate of speciation. Likewise, human-assisted invasions are effectively breaking down biogeographical barriers, and the resulting global mixing renders idle one of the most prolific means of generating biodiversity: isolation. If we cannot stop this Macdonaldization of the biosphere, we stand to lose a substantial part of global biodiversity and may well find that we need variety not just as the spice of life — but for life itself. 